\title{
LIV. On certain small corrections in a newton's- rings system
}

\section{Allan Ferguson B.Sc.}

To cite this article: Allan Ferguson B.Sc. (1913) LIV. On certain small corrections in a newton's-rings system , Philosophical Magazine Series 6, 25:148, 501-506, DOI: $10.1080 / 14786440408634190$

To link to this article: http://dx.doi.org/10.1080/14786440408634190

册 Published online: 08 Jun 2010.

Submit your article to this journal $[\pi$

Џ Article views: 6

Q View related articles $\square$

Citing articles: 1 View citing articles 5 
Corrections in a Newton's-rings System.

501

\begin{tabular}{|c|c|c|c|}
\hline Type. & Principle employed. & Reference. & $\begin{array}{l}\text { Smallest } \\
\text { detectable pressure. }\end{array}$ \\
\hline $\begin{array}{l}\begin{array}{l}\text { Rayleigh } \\
\text { Morley \& Brush } \\
\text { Threlfall }\end{array} \\
\text { Hering } \\
\text { Sche................ } \\
\text { Chattock \& Fry... }\end{array}$ & $\begin{array}{l}\text { Tilting mercury U-tube. } \\
", " \\
\text { Micrometer screw ad- } \\
\text { justments to surfaces } \\
\text { of water U-tube. } \\
\text { Tilting mercury U-tube } \\
\text { with electric contacts. } \\
\text { Metal diaphragm witl } \\
\text { interference fringes. } \\
\text { Tilting water U-tube } \\
\text { with benzene bubble } \\
\text { indicator. } \\
\end{array}$ & $\begin{array}{l}\text { Phil. Trans. A 196, } \\
\text { p. 205 (1901). } \\
\text { Auner. Journ. Sci. xiii. } \\
\text { June 1902. } \\
\text { Inst. Mech. Eng. Proc. } \\
\text { Feb. 1904, p. 273. } \\
\text { Ann. d. Phys. xxi. 1906. } \\
\text { Deutsch. Phys. Gesell. } \\
\text { Jan. 1909. } \\
\text { Stanton, Proc. Inst. C.E. } \\
\text { clvi. } \\
\text { Morrow, P. R. S. A 76, } \\
\text { 1905. } \\
\text { Chattock \& Tyndall, } \\
\text { Phil. Mag. xix. p. } 450 \\
\text { (1910). Tyndall, Phil. } \\
\text { Fry \& Ty. } \\
\text { Mag. xxi. p.348(1911). }\end{array}$ & 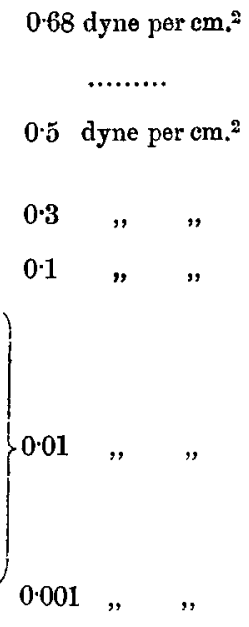 \\
\hline
\end{tabular}

Experiments on a manometer of this type for use at low absolute pressures are now in progress.

University of Bristol.

Jan. 1913.

LIV. On certain Small Corrections in a Newton's-rings System. By Allan Ferguson, B.Sc. (Lond.), Assistant Lecturer in Physics in the University College of North Wales, Bangor *.

T $N$ the progress of some experimental work which demanded 1 the production and examination of a system of Newton's rings formed under oblique incidence, it seemed that measurements of the diameters of the rings-which, of course, viewed under oblique incidence appear ellipticalwould furnish an accurate and easy method for the determination of the angle of incidence.

For if the rings be viewed through a microscope provided with independent vertical and horizontal scales, and the

* Communicated by Professor E. Taylor Jones. 
minor axes of the ellipse be measured on the vertical scale, then, as the figure shows,

Fig. 1.

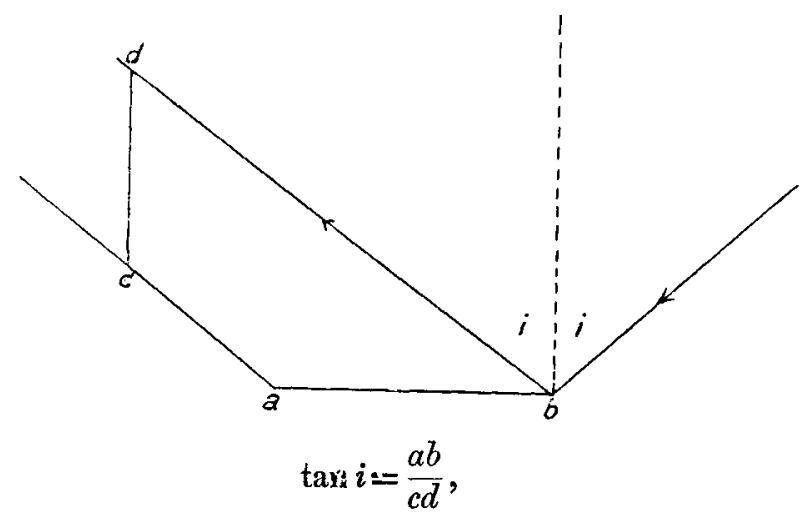

if we assume that the rings are truly circular, and concentric with the point of contact of the surfaces between which they are formed, so that $a b$ may be assumed to be given by the measurement of the major axis of the ellipse.

Such a method is probably more satisfactory than those which depend on the measurement of the inclination either of microscope or collimating system, but its use obviously depends on the correctness of the assumption italicised above.

This assumption again depends on the manner in which the equations of the ring-curves are formed. It is a remarkable fact that, even in the definitive treatises on the subject, it is tacitly-or, as for example in the case of Airy's "Undulatory Theory," overtly-assumed that the parallel-plate formulæ can be used without modification, and this, despite the fact that there is a somewhat extensive literature dealing with the subject ${ }^{*}$. The papers cited below deal fairly exhaustively with a variety of points of importancee.g. the exact shape of the interference surfaces, and the plane in which the fringes are formed-but the expressions arrived at are somewhat cumbrous in form, and not well adapted for practical use.

The variety and importance of the measurements of physical quantities which depend on the production of interference systems, are such as render it desirable to put

* See e. g., Wangerin, Pogg. Ann. cxxxi. p. 497 (1867) ; Feussner, Wied. Ann. xiv. p. 564 (1881); Sohncke and Wangerin, Wied. Ann. xii. pp. 1 \& 207 (1881), and Wied. Ann. xx. pp. 177 \& 391 (1883); Mascart, Traité d'Optique, i. pp. 439 seqq. 
into convenient form the more important of the abovementioned corrections.

In the analysis here given a different course is followed. Whilst only attempting to provide a first approximation, it is hoped that it will show clearly the conditions under which the parallel-plate formulæ can be used, and the magnitude of the correction to be applied in the cases of practical importance where the use of the parallel-plate formulp is not: legitimate.

Suppose, then, that we have a plano-convex lens resting on a plane reflecting surface. The central assumption usually made is that $\phi$, the angle of incidence of the light on the lower reflecting surface, is, to the first order, the same as the angle of incidence $i$ of the light on the upper plane surface of the lens. In which case the well-knowu relation

$$
2 \mu e \cos i=n \lambda \text {. . . . . . }
$$

gives at once for the radius $x$ of the $n$th dark ring

$$
x^{2}=\mathrm{R} n \lambda \sec i \text {. }
$$

For our purpose, it will be sufficiently exact to determine $\phi$ as a function of $i$, and to substitute the value of $\cos \phi$ so obtained in the equation

$$
2 \mu e \cos \phi=n \lambda \text {. }
$$

Fig. 2.

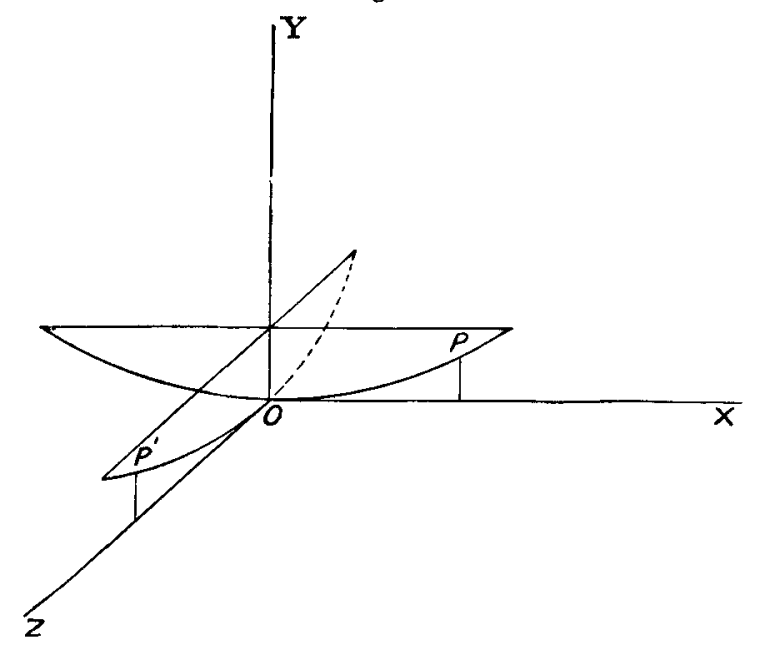

Two cases are of special interest.

Taking rectangular axes as shown(fig. 2), let light be incident at an angle $i$ on the upper surface of the lens in a plane 
parallel to the plane of $x y$. We shall consider the magnitude of the correction to be applied for light which, after refraction at the upper surface of the lens, is incident at the symmetrical points $\mathrm{P}$ and $\mathrm{P}^{\prime}$.

Let $\mathrm{R}$ be the radius of the lens-surface and $x$ the radius of the $n$th dark ring, and let us assume in what follows that $\frac{x^{2}}{\mathrm{R}^{2}}$ and $\tan ^{2} \psi\left(\tan \psi \equiv \frac{d y}{d x}\right)$ are negligible compared with unity. Taking first the case in which the refraction occurs at $P$, we have from fig. 3

Fig. 3.

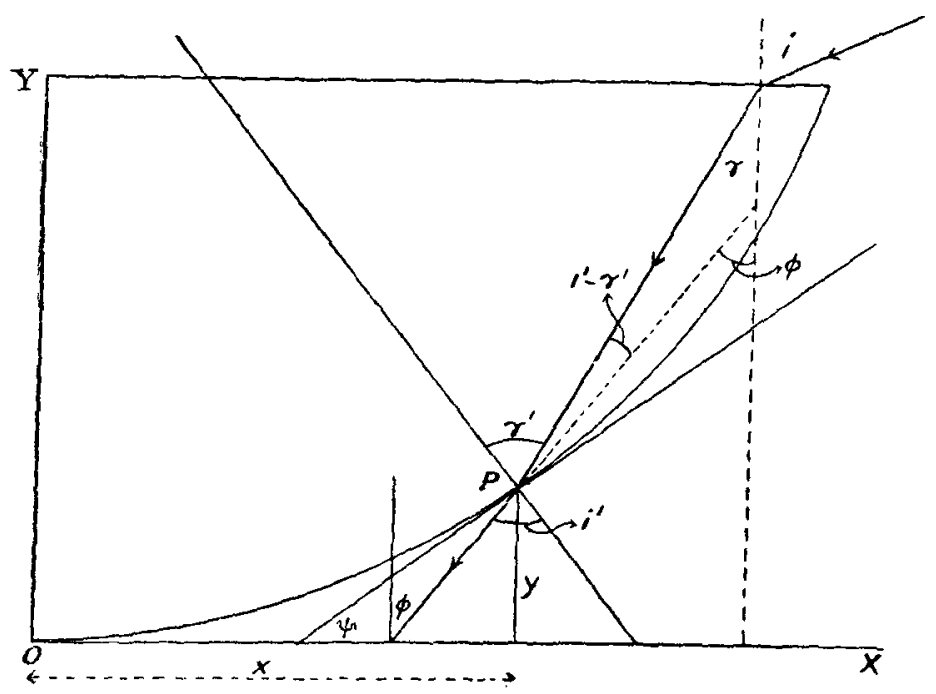

$$
\text { and } \begin{aligned}
& \phi=i^{\prime}-r^{\prime}+r, \quad . \quad . \quad . \quad . \\
& \psi=i^{\prime}-\phi .
\end{aligned}
$$

Also, if the origin be at $O$,

$$
x^{2}+y^{2}-2 \mathrm{R} y=0,
$$

$$
\text { and therefore } \tan \psi=\frac{d y}{d x}=\frac{x}{\mathrm{R}-y},
$$

giving

$$
\sin \psi=\frac{x}{\mathrm{R}}=p, \text { say. }
$$


Again,

$$
i^{\prime}-\phi=\psi=\tan \psi=\sin \psi=p, . . .
$$

to the order considered, which, combined with (ii.), gives

\section{Hence}

$$
r^{\prime}=r+p \text {. }
$$

$$
\sin i^{\prime}=\mathrm{N} \sin r^{\prime}=\mathrm{N} \sin (p+r)=\mathrm{N}(p \cos r+\sin r) .
$$

Similarly from (iii.),

$$
\sin i^{\prime}=\sin (p+\phi)=p \cos \phi+\sin \phi,
$$

and therefore $p \cos \phi+\sin \phi=\mathrm{N}(p \cos r+\sin r)$,

which, solving for $\cos \phi$ and reducing, gives

$$
\cos \phi=\cos i+\frac{x}{\mathbf{R}} \sin i\left\{1-\frac{\sqrt{\mathrm{N}^{2}-\sin ^{2} i}}{\cos i}\right\} .
$$

Hence $\cos \dot{\phi}$ is not equal to $\cos i$, but is subject to a small first-order correction. It is important to notice that the correction vanishes to the first order for normal incidence.

Turning now to the case (fig. 2) where the ray is incident at $\mathbf{P}^{\prime}$, a point in the $\mathrm{YZ}$ plane, the direction-cosines of the ray after refraction at the plane surface of the lens are

$$
l_{2}=\sin r, \quad m_{2}=\cos r, \quad n_{2}=0 .
$$

If the tangent at $P^{\prime}$ makes an angle $\psi$ with $\mathrm{OZ}$, the directioncosines of the normal at $\mathrm{P}^{\prime}$ are

$$
p^{\prime}=0, \quad q^{\prime}=\cos \psi, \quad r^{\prime}=\cos \left(90^{\circ}+\psi\right)=-\sin \psi .
$$

Then if $\phi_{1}$ and $\phi_{2}$ be the angles between the ray and the normal before and after refraction at $\mathrm{P}^{\prime}, l_{3}, m_{3}, n_{3}$ the direction-cosines of the ray after refraction at $\mathrm{P}^{\prime}$,

$$
\begin{aligned}
& \cos \phi_{1}=m_{2} q^{\prime}=\cos r \cos \psi, \\
& \cos \phi_{2}=m_{3} \cos \psi-n_{3} \sin \psi .
\end{aligned}
$$

From the general formulæ for refraction, where $\mu$ and $\mu^{\prime}$ are the "absolute" refractive indices for glass and air* (so that $\frac{\mu}{\mu^{\prime}}=\mathrm{N}$ ),

$$
\left.\begin{array}{c}
\mu l_{2}-\mu^{\prime} l_{3}=\left(\mu \cos \phi_{1}-\mu^{\prime} \cos \phi_{2}\right) x^{\prime}, \\
\mu m_{2}-\mu^{\prime} m_{3}=\left(\mu \cos \phi_{1}-\mu^{\prime} \cos \phi_{2}\right) q^{\prime}, \\
\mu n_{2}-\mu^{\prime} n_{3}=\left(\mu \cos \phi_{1}-\mu^{\prime} \cos \phi_{2}\right) r^{\prime} .
\end{array}\right\} . .
$$


From the first of these we have

$$
\text { and therefore } \quad \begin{aligned}
\mu l_{2}-\mu^{\prime} l_{3} & =0, \\
l_{3} & =\mathrm{N} \sin r,
\end{aligned}
$$

Hence

$$
m_{3}{ }^{2}+n_{3}{ }^{2}=1-l_{3}{ }^{2}=1-\mathrm{N}^{2} \sin ^{2} r . \quad \text {. . . (v.) }
$$

From the second or third of (iv.) we obtain

$$
m_{3} \sin \psi+n_{3} \cos \psi=\mathrm{N} \cos r \sin \psi \text {. }
$$

Substituting this value of $n_{\mathrm{a}}$ in (v.), we obtain, if $\tan ^{2} \psi$ be negligible compared with unity,

$$
m_{3}^{2}=1-\mathrm{N}^{2} \sin ^{2} r=\cos ^{2} i .
$$

If, then, $\phi$ be the angle between the ray in the film and a line parallel to $O Y$ whose direction-cosines are therefore $0,1,0$, we have from the usual formula

$$
\cos \phi=m_{3}=\cos i \text {. }
$$

It seems, then, that the correction, which is of the first order in the plane of $X Y$, and only vanishes there at normal incidence, is of the second order in the $\mathrm{YZ}$ plane, vanishing there for all angles of incidence. These results are in substantial agreement with those of Wangerin *.

If it be desired, therefore, to eliminate first-order corrections, the analysis points to the following experimental precautions. ( $\alpha$ ) Either the light must be used at normal incidence, or $(\beta)$ if obliquely incident light be used, measurements must be restricted to those rings for which $\frac{x}{\mathrm{R}}$ is small compared with unity. But, in this case, it is only to the measurement of diameters in the plane of incidence to which this restriction applies. Even with oblique incidence the diameters of the rings measured perpendicularly to the plane of incidence are only subject to a second-order correction. 